Revista Iberoamericana

de las Ciencias Sociales y

Humanísticas

ISSN: 2395 - 7972

https://doi.org/10.23913/ricsh.v10i19.242

Artículos científicos

\title{
El reto de la educación 4.0: competencias laborales para el trabajo emergente por la covid-19
}

The challenge of education 4.0: labour skills for emerging work by covid-19 O desafio da educação 4.0: competências laborais para o trabalho
emergente devido a covid-19

Gabriela Mendizábal Bermúdez Universidad Autónoma del Estado de Morelos, México

gabymendizabal@yahoo.com.mx mgabriela@uaem.mx https://orcid.org/0000-0003-3681-4025

Ana Esther Escalante Ferrer Universidad Autónoma del Estado de Morelos, México anaescalante7@hotmail.com ana.escalante@uaem.mx https://orcid.org/0000-0003-2005-3436

\section{Resumen}

La cuarta revolución industrial ha generado grandes cambios en la vida de las personas, principalmente en el ámbito educativo y laboral. Surgen nuevas profesiones y otras desaparecen, de ahí que los sistemas educativos de cada país deban adaptarse a las necesidades para preparar a los futuros profesionistas de un mercado laboral cambiante e incierto. En ese contexto, la educación 4.0 se presenta como un modelo flexible y adaptativo que se caracteriza por apoyarse en las tecnologías de la información y la comunicación y, principalmente, en las tecnologías de la digitalización de la industria 4.0. A esa realidad se le debe sumar que en el año 2020 la pandemia provocada por el virus Sars-CoV2 ha revolucionado y acelerado precisamente el uso de las tecnologías en el desarrollo de los 


\section{Revista Iberoamericana de las Ciencias Sociales y Humanísticas}

trabajos y en los procesos formativos de todos los niveles, por lo que en el presente estudio se describen los retos de la educación 4.0 impuestos por la industria 4.0 y por la pandemia. Este artículo, en síntesis, incluye los resultados de una investigación documental sobre las competencias laborales que deben adquirir los estudiantes universitarios para incorporarse y ser competitivos en el desarrollo del trabajo emergente por la covid-19. El método utilizado fue el analítico-deductivo, el cual permitió desarrollar un marco conceptual y contextual, así como analizar la situación del mundo laboral vigente y las directrices sobre el tema de los principales organismos internacionales (Organización Internacional del Trabajo, Organización de las Naciones Unidas para la Educación, la Ciencia y la Cultura, Comisión Económica para América Latina y el Caribe, Organización para la Cooperación y el Desarrollo Económicos y la Unión Europea). En conclusión, se puede decir que las competencias necesarias para desenvolverse en este nuevo ámbito son seis: pensamiento crítico y solución de problemas complejos; competencias digitales laborales; competencias socioemocionales para el trabajo 4.0; competencias para el trabajo transdisciplinar; competencias de aprendizaje permanente (saber reaprender), y competencias lingüísticas.

Palabras clave: competencias laborales, covid-19, cuarta revolución industrial, educación 4.0, virus Sars-Cov2.

\section{Abstract \\ The Fourth Industrial Revolution has generated great changes in people's lives, but mainly in the educational and work environment. New professions arise and others disappear and for this reason, the educational systems of each country must adapt to the needs to prepare future professionals for a changing and uncertain labor market. In this context, education 4.0 is presented as a flexible, adaptive model, which is also characterized by incorporating information and communication technologies and mainly the digitalization technologies of industry 4.0. In addition, in 2020 the pandemic due to the Covid-19 virus has precisely revolutionized and accelerated the use of technologies in the development of jobs and in training processes at all levels. Due to this fact it is essential to analyze what are the new challenges for education 4.0 imposed by industry 4.0 and the pandemic. This article includes the results of a documentary research on the job skills that university students must acquire in order to join and be competitive in the development of emerging work due to Covid-19.}




\section{Revista Iberoamericana de las Ciencias Sociales y Humanísticas}

The research method used was the analytical-deductive one, concluding, after the development of a conceptual and contextual framework, the analysis of the current work situation worldwide and the guidelines of the main international organizations (International Labor Organization, United Nations Educational, Scientific and Cultural Organization, Economic Commission for Latin America and the Caribbean, Organization for Economic Cooperation and Development and the European Union),

it could be concluded that the competencies are 6: critical thinking and complex problem solving; Digital job skills; Socio-emotional skills for work 4.0; Competences for transdisciplinary work; Lifelong learning skills (knowing how to relearn) and Language skills.

Keywords: job skills, covid-19, fourth industrial revolution, education 4.0, virus SARS$\mathrm{CoV} 2$.

\section{Resumo}

A quarta revolução industrial gerou grandes mudanças na vida das pessoas, principalmente na educação e no trabalho. Novas profissões surgem e outras desaparecem, portanto os sistemas educacionais de cada país devem se adaptar às necessidades de preparar os futuros profissionais para um mercado de trabalho em mudança e incerto. Neste contexto, a educação 4.0 apresenta-se como um modelo flexível e adaptativo que se caracteriza por contar com as tecnologias de informação e comunicação e, principalmente, com as tecnologias de digitalização da indústria 4.0. A esta realidade acrescenta-se que em 2020 a pandemia provocada pelo vírus Sars-CoV2 precisamente revolucionou e acelerou o uso de tecnologias no desenvolvimento de empregos e nos processos de formação a todos os níveis, pelo que Este estudo descreve os desafios da educação 4.0 impostos pela indústria 4.0 e pela pandemia. Este artigo, em síntese, inclui os resultados de uma pesquisa documental sobre as competências para o trabalho que os estudantes universitários devem adquirir para ingressar e ser competitivo no desenvolvimento de trabalhos emergentes devido ao covid-19. O método utilizado foi o analítico-dedutivo, o que permitiu desenvolver um quadro conceitual e contextual, bem como analisar a situação atual do mercado de trabalho e as diretrizes sobre o tema das principais organizações internacionais (Organização Internacional do Trabalho, Organização das Nações Unidas para a Educação, Ciência e Cultura, Comissão Econômica 


\section{Revista Iberoamericana de las Ciencias Sociales y Humanísticas}

ISSN: $2395-7972$

para a América Latina e o Caribe, Organização para Cooperação e Desenvolvimento Econômico e União Européia). Concluindo, pode-se dizer que as competências necessárias para funcionar neste novo campo são seis: pensamento crítico e resolução de problemas complexos; competências de trabalho digital; competências socioemocionais para o trabalho 4.0; competências para o trabalho transdisciplinar; competências de aprendizagem ao longo da vida (saber reaprender) e competências linguísticas.

Palavras-chave: competências laborais, covid-19, quarta revolução industrial, educação 4.0, vírus Sars-Cov2.

Fecha Recepción: Abril 2020

Fecha Aceptación: Diciembre 2020

\section{Introducción}

La cuarta revolución industrial —en el contexto de la actual pandemia generada por la covid-19- ha ocasionado que las formas de laborar cambien drásticamente, pues se ha pasado de un trabajo colaborativo entre hombre-máquina a una automatización completa (máquina-máquina) de los procesos de producción. Esto ha provocado que se encuentren en riesgo labores fácilmente automatizables por las inteligencias artificiales, aunque también es cierto que han surgido nuevas profesiones (p. ej., arquitecto de datos, nanomédicos, especialistas en big data, entre otros) (Menéndez, 2020).

En el campo de la educación, la covid-19 también ha obligado a pasar de lo presencial a lo virtual, por lo que ha crecido la necesidad de determinar las competencias tecnológicas y laborales que se deben desarrollar para cumplir con los objetivos establecidos. En este sentido, Galindo (2015) y Gasca (2010) apuntan que, en principio, se deben reconocer las diferencias que hay entre la lectura en medios impresos y digitales, mientras que Lombardero (2015) hace énfasis en que las destrezas indispensables para desenvolverse en el mundo virtual no necesariamente tendrán que ser producto de una formación profesional, sino que pueden ser certificables en entornos formativos más flexibles.

Swain Oropeza (2017) describe las revoluciones industriales y reconoce que en México no hay avances para adecuar esas transformaciones a la educación superior. Por eso, su propuesta curricular, basada en retos para el área de ingeniería, se enfatiza en promover la vinculación universidad-empresa e impulsar la formación integral del estudiante, en especial

el desarrollo de las competencias blandas (trabajo en equipo, liderazgo, flexibilidad, entre otras). 


\section{Revista Iberoamericana de las Ciencias Sociales y Humanísticas}

Quiroz y Norzagaray (2017), por su parte, desarrollan un estudio cuantitativo con el objetivo de indagar en las prácticas académicas de educación superior que se realizan con dispositivos y herramientas tecnológicas. Los resultados permiten concluir a las autoras que los alumnos muestran habilidad para la localización de información, pero no para su integración o para la generación de ideas propias.

Garay (2017) describe las acciones de los estudiantes de educación superior para fortalecer habilidades digitales que puedan ser empleadas fuera de la escuela y cómo estas son incorporadas a actividades de participación de colectivos estudiantiles y para el trabajo 4.0. Echeverría y Martínez (2018) analizan las transformaciones económicas y laborales del flujo que enfrentarán las profesiones, por lo que destaca la obligación de cultivar competencias como las siguientes: “a) pensamiento crítico, comprensión y capacidades de análisis; b) integrar la alfabetización de los nuevos medios (de comunicación) en los programas educativos; c) incluir el aprendizaje en la práctica" (p. 13); asimismo, sugieren la consolidación de habilidades como la inteligencia emocional y la flexibilidad cognitiva.

Por su parte, autores como Irigoin y Vargas (2002) y Menéndez (2020) señalan la concepción de las competencias laborales y las nuevas profesiones que tendrán éxito en un futuro inmediato, así como las que desaparecerán en un futuro cercano. Al respecto, Ynzunza, Izar, Bocarando, Aguilar y Larios (2018) llegan a la conclusión de que las transformaciones tecnológicas asociadas con la industria 4.0 y la manufactura inteligente tendrán repercusiones positivas y negativas en la producción, lo que exigirá de las instituciones educativas la formación de profesionales especializados para las demandas del mercado laboral.

Lahera (2019), en cambio, considera que la digitalización causará un desempleo masivo, aunque también cree que algunas profesiones deberán ser reestructuradas, por lo que sugiere "intervenir en los sistemas de formación y el reciclaje del factor humano" (p. 263), es decir, preparar a las personas para adaptarse a nuevas actividades.

Como puede observase, las coincidencias de los distintos trabajos revisados muestran una preocupación por los embates del cambio y la función de la educación superior para atender el desarrollo de las competencias requeridas para enfrentar las nuevas condiciones.

Ahora bien, aunque las anteriores opiniones son muy relevantes, cabe resaltar que no se encontraron estudios sobre las competencias que se requieren para hacer frente al mercado laboral trastocado por la covid-19. Este tema, por ende, resulta particularmente importante en medio de una nueva realidad que requiere cambios drásticos, de ahí que se hayan 


\section{Revista Iberoamericana \\ de las Ciencias Sociales y Humanísticas}

ISSN: 2395 - 7972

establecido las siguientes preguntas de investigación: ¿cuál es el reto de la educación 4.0 ante la pandemia originada por la covid-19? y ¿cuáles son las competencias que debe desarrollar el mercado laboral para afrontar las necesidades que imponen la industria 4.0 y la pandemia?

Una de las hipótesis planteadas fue que las ya determinadas competencias genéricas y disciplinares deben tener una extensión para ahora hacer frente a la revolución tecnológica, pues en la actualidad para ser un profesionista exitoso se necesitan no solo conocimientos, habilidades y destrezas disciplinares, sino también habilidades digitales, idiomáticas, socioemocionales, etc. En pocas palabras, el verbo reaprender será el pilar clave para no quedar desfasados en los nuevos trabajos especializados, sobre todo en aquellos donde predomine lo digital.

\section{Objetivos}

El objetivo general de esta investigación fue determinar cuáles son los retos de la educación 4.0 - en el contexto de la pandemia - para formar adecuadamente a los estudiantes universitarios, de modo que puedan incorporarse a un mercado laboral completamente cambiante. Para conseguir tal propósito se establecieron los siguientes objetivos específicos:

Demostrar que existe una coincidencia en competencias para el trabajo emergente determinadas por los principales organismos internacionales, los cuales estudian el trabajo y sus efectos, y han emitido directrices.

Analizar cada una de las competencias que se consideran indispensables para hacer frente al trabajo en la cuarta revolución industrial y determinar cuáles se requieren dentro del cambio que se ha generado en el trabajo durante el periodo de la pandemia.

\section{Metodología}

Los resultados que se presentan en este artículo corresponden a las conclusiones de una investigación de tipo documental y descriptiva, desarrollada con base en el método analíticodeductivo. Para ello, primero se reseña el entorno actual que se vive en el mundo, así como las consecuencias de la cuarta revolución industrial y de la pandemia generada por la covid19. Esta parte descriptiva configura el marco contextual que sirve de base para entender la problemática a la que se enfrenta la formación para el trabajo en la actualidad. 


\section{Revista Iberoamericana \\ de las Ciencias Sociales y Humanísticas}

ISSN: 2395 - 7972

Posteriormente, siguiendo el método deductivo, se analizan diversos conceptos, como industria 4.0, educación 4.0, competencias, entre otros, los cuales se entretejen en la investigación conformando un marco conceptual que tiene un doble objetivo: por una parte, fijar la postura de las autoras en relación con esos temas y, por la otra, delimitar la visión con la que se debe entender el tratamiento de la información analizada.

Debido a que se trata de una investigación de corte doctrinal - cuyo estado de la cuestión demostró que los principales organismos internacionales han emitido directrices antes de la pandemia sobre el rumbo que la formación profesional debe seguir para responder a las necesidades laborales, y en seguimiento del método deductivo - se demuestra que las competencias que se están requiriendo para la transformación del trabajo son las mismas que se exigen para pasar de lo presencial al home office o teletrabajo.

\section{Resultados}

Este artículo ofrece resultados que se presentan en una discusión conformada por cuatro apartados: el primero se enfoca en el contexto de la pandemia generada por la covid19. El segundo establece las bases para la comprensión de la cuarta revolución industrial y la educación 4.0. En el tercero se analizan los cambios provocados en el mundo laboral por la industria 4.0 y por la covid-19. Estos primeros tres apartados sirven de base para comprobar que el reto de la educación 4.0 es formar profesionistas con competencias laborales para la cuarta revolución industrial, y para el trabajo emergente por la covid-19, tema del cuarto apartado.

El mayor aporte de la investigación fue determinar que el mayor reto de la educación 4.0 en tiempos de la pandemia y de la cuarta revolución industrial es lograr la adquisición de las siguientes competencias para el trabajo emergente: pensamiento crítico y solución de problemas complejos, competencias digitales laborales, competencias socioemocionales para el trabajo 4.0, competencias para el trabajo transdisciplinar, competencias de aprendizaje permanente (saber reaprender) y competencias lingüísticas. 


\section{Revista Iberoamericana \\ de las Ciencias Sociales y Humanísticas}

\section{Contexto de la pandemia ocasionada por el covid-19}

La Organización Mundial de la Salud (OMS) (2020) establece que la covid-19 es una enfermedad infecciosa causada por una cepa de coronavirus ${ }^{1}$ descubierta recientemente. Tanto este nuevo virus como la enfermedad que provoca eran desconocidos antes de que estallara el brote en China en diciembre de 2019.

En el mes de marzo de 2020, la OMS explicó que debido al aumento de contagios por el virus Sars-CoV2, surgió la necesidad de categorizar a la enfermedad como pandemia, razón que obligó a todos los países a tomar acciones inmediatas (Organización Panamericana de la Salud, [OPS] 2020), como el cierre temporal de las fuentes de trabajo que no eran consideradas esenciales, así como la suspensión de las clases presenciales, por lo que se debían diseñar estrategias digitales para terminar el ciclo escolar.

De las acciones gubernamentales de cada país se desprende un par de cuestionamientos que involucran los dos puntos focales para el presente trabajo. El primero es que muchas de las fuentes de empleo consideradas como no esenciales tuvieron que adaptarse a la modalidad de teletrabajo, lo cual no era tan novedoso para algunos países; sin embargo, para naciones en vías de desarrollo implementar esta modalidad complicó seriamente las condiciones laborales, pues la falta de ciertas herramientas (como el acceso a una computadora e internet), el cuidado de hijos, adultos mayores y familiares enfermos, así como la convivencia en confinamiento pusieron a prueba la estabilidad emocional de toda la población, en especial de las trabajadoras debido a los estereotipos de género.

En segundo lugar, la pandemia obligó la impartición de clases por medios digitales. Este hecho supuso un reto para profesores y estudiantes, ya que ambos necesitaban contar con competencias tecnológicas para desempeñarse de manera eficaz en las plataformas. En pocas palabras, la pandemia sirvió para poner al descubierto las carencias de los sistemas de salud, de las empresas en general y de los centros educativos en particular.

\footnotetext{
${ }^{1}$ Los coronavirus son una extensa familia de virus que pueden causar enfermedades tanto en animales como en humanos. En los humanos, se sabe que varios coronavirus causan infecciones respiratorias que pueden ir desde el resfriado común hasta enfermedades más graves, como el síndrome respiratorio de Oriente Medio (MERS) y el síndrome respiratorio agudo severo (SRAS).
} 


\section{Cuarta revolución industrial y educación 4.0}

El término industria 4.0 fue usado oficialmente por primera vez en 2011 para referirse a un modelo que se basa, eminentemente, en la aplicación de las nuevas tecnologías dentro de los procesos de producción con el fin de hacerlos autómatas, inteligentes y eficientes. Aunque es aventurado ofrecer una sola definición para dicho concepto (Castresna, 2015), se pueden mencionar sus elementos principales, los cuales se enumeran a continuación:

1. Nuevo modelo de organización: Este rompe los esquemas tradicionales de trabajar entre personas o de interacción hombre-máquina. Ahora el esquema se caracteriza, principalmente, por la relación máquina-máquina sin la intervención humana (Mendizábal y López, 2018).

2. Sistemas automatizados: Para lograr un sistema automatizado se involucran dos aspectos muy importantes: la digitalización y el internet de las cosas.

3. Tecnologías de la información y de comunicación (TIC): Las TIC son un factor primordial para el desarrollo de los sistemas automáticos en la cuarta revolución industrial, pues son "las tecnologías" que se necesitan para la gestión y transformación de la información" (Sánchez, 2008, p. 156) [cursivas añadidas]. Es decir, son el medio conductor por el cual se pretenden realizar alguna acción, esto es, ordenadores, programas, etc., que permitan crear, modificar y almacenar información.

4. Producción eficiente: En esta cuarta revolución industrial se plantea como objetivo principal la producción de bienes o servicios en menor tiempo y costo, pero con una mayor calidad para beneficiar a las empresas y a los clientes; sin embargo, cabe resaltar que el trabajador puede ser uno de los principales afectados.

5. Interacción directa del cliente: Un punto que caracteriza a esta cuarta revolución industrial es la intervención directa del cliente en el proceso de producción del bien y/o servicio (on-demand economy), pues desde la comodidad de su casa - y gracias al uso de las TIC — puede ordenar el producto según las características que desee. Esto no solo permite considerar los anhelos individuales del cliente, sino también desarrollar productos industriales y modelos comerciales completamente nuevos.

\footnotetext{
${ }^{2}$ Según el Diccionario de la Real Academia Española, la tecnología es el conjunto de los instrumentos y procedimientos industriales de un determinado sector o producto.
} 
Podemos afirmar, por tanto, que la industria 4.0 exige un nuevo modelo de organización, de ahí que Deloitte (2019) explique lo siguiente:

La cuarta revolución industrial es el fenómeno social, económico y político que se caracteriza por el cambio constante y la generación de nuevas formas de producción, consumo, comunicación y enseñanza-aprendizaje, entre otras, con base en el uso de las tecnologías de la digitalización, que impactan al ser humano en su cotidianidad (cómo nos relacionamos, trabajamos y vivimos) (p. 3).

Como se puede inferir de los párrafos anteriores, esta revolución tecnológica y la situación causada por la covid-19 han provocado que la mayoría de los campos laborales (entre ellos el educativo) deban ser reestructurados, por lo que las instituciones de educación de ahora deben preparar a profesionistas que posean competencias específicas para desenvolverse con éxito en la realidad inmediata.

En tal sentido, la Organización para la Cooperación y el Desarrollo Económico (OCDE) (2019) sugiere la desprofesionalización y el aprendizaje basado en el trabajo para formar a ciudadanos que puedan desarrollar los conocimientos, las actitudes y los valores que necesitan a lo largo de la vida. Aquí cobra vital importancia el binomio educación-trabajo basado en las principales tendencias de innovación y cambio. El modelo 4.0, por ende, debe promover el rescate de los elementos de la educación tradicional para combinarlos con los avances emergentes y las propuestas de la ciencia del siglo XXI (Fundación Mapfre, 2019).

La educación 4.0, entonces, es una propuesta formativa que tiene la intención de preparar a los profesionistas del futuro con las competencias que les permitirán acceder a los empleos que están apareciendo como consecuencia de las transformaciones en el mundo del trabajo (Universidad Autónoma del Estado de Morelos [UAEM], 2020). Este modelo es flexible, adaptativo y se caracteriza porque se apoya en las TIC y principalmente en la inteligencia artificial, la analítica de datos, la gamificación, entre otras (Cataldi y Dominighini, 2015).

\section{Cambios en el trabajo}

Como se mencionó anteriormente, el mundo del trabajo está viviendo un fuerte cambio, por lo que se pronostica la desaparición y el surgimiento de algunas profesiones. 


\section{Profesiones que desaparecerán}

El Foro Económico Mundial (FEM) (2018) en su publicación Future of jobs estableció que derivado de la automatización en los procesos de producción se eliminarán 75 millones de empleos a nivel mundial para 2025. Profesiones que se encuentran estrechamente vinculadas con trabajos automatizados o que sus funciones pueden ser automatizadas de una manera sencilla y realizadas por una máquina a través de la inteligencia artificial serán las primeras en desaparecer. Algunas de ellas se mencionan a continuación:

- Agentes de viajes, ya que hoy en día cualquier persona puede reservar sus vacaciones desde la comodidad de sus casas, sin la necesidad de algún intermediario que se encargue de ello.

- Empleados de call center: Las máquinas serán las que ocupen estos puestos en un corto plazo, ya que las funciones de este puesto son fácilmente automatizables.

- Cartero: Los servicios de correo se verán severamente reducidos por los e-mail.

- Ejecutivos bancarios: Una realidad no muy lejana, pues actualmente se han introducido a lo largo del país centros de atención a clientes controlados por máquinas, las cuales se encuentran programadas para resolver los principales problemas que un usuario bancario puede tener con su cuenta.

- Traductores: Solo basta abrir una aplicación para traducir un documento en cualquier idioma.

- Trabajadores de cabina de estacionamientos, cines, peaje, supermercados, entre otros. Una máquina ya es capaz de realizar la actividad de cobro de manera automática.

\section{Nuevas profesiones}

Debido al avance vertiginoso de la tecnología, en el futuro cercano habrá vacantes, por ejemplo, en el campo de la arquitectura de datos, disciplina que se encargará de diseñar estrategias para sistemas de base de datos de las empresas y estándares de operaciones, programación y seguridad (Federal Student Aid, s. f.). Asimismo, commerce manager, que se especializará en el “comercio electrónico o tienda online de la compañía con el objetivo de hacerlo crecer" (Blanco, 19 de julio de 2018, párr. 15). En pocas palabras, los nuevos empleos se podrán dividir según las siguientes categorías: 
- Funciones humanizadoras: Aquellos trabajos que se encuentran enfocados en la inteligencia emocional y las relaciones interpersonales podrán ser más valiosos en esta era tecnológica (Linkedin, 2017).

- Trabajos de ciencias de datos, ingeniería y aprendizaje automático: Existirá un gran crecimiento de fuentes de trabajo centradas en la aplicación de este tipo de ciencias exactas con la finalidad de mejorar y construir nuevas máquinas (Linkedin, 2017).

- Formadores y capacitadores de inteligencia artificial: Este campo estará dirigido a aquellas personas que se encuentren ampliamente entrenadas para poder desarrollar el lenguaje comunicativo de las máquinas, capaces de corregir los problemas que se presenten y mantener actualizadas las inteligencias artificiales que se desarrollen (Linkedin, 2017).

- Profesiones tradicionales con nuevas formas de trabajar: Los trabajos tradicionales se fusionarán con las nuevas tecnologías, lo que permitirá un mejor desempeño en las actividades; por ejemplo, en el ámbito de la salud los médicos tendrán que manejar los nuevos robots que hacen cirugías más precisas.

- Nuevas formas de trabajar: Gracias a la comunicación mediante internet se ha abierto la oportunidad de fomentar el teletrabajo.

\section{Competencias laborales para la cuarta revolución industrial y el trabajo emergente por la covid-19}

Este tema se ha dividido en tres apartados: competencias laborales, retos de la educación 4.0, y competencias para el trabajo emergente en tiempos de la cuarta revolución industrial y la covid-19.

\section{Competencias laborales}

Desde el enfoque pedagógico constructivista, la definición de competencia tiene su origen en las obras de Piaget, Bruner, Vigotsky y Ausbel. Perrenoud (2004) sintetiza las propuestas de los teóricos mencionados y ve a las competencias como las capacidades que movilizan recursos (conocimientos, valores y actitudes) que si se conectan entre sí, permiten la atención a los problemas que se enfrentan tanto en la vida diaria como en los entornos de interacción social. 


\section{Revista Iberoamericana de las Ciencias Sociales y Humanísticas}

El énfasis en el desarrollo de competencias estriba en el involucramiento de quien aprende, de ahí que se recupere de Ausbel (1990) la noción de aprendizaje significativo, el cual se logra cuando un nuevo conocimiento es relacionado con la experiencia previa del estudiante. Es decir, se reconoce que para que se dé un aprendizaje se requiere de un procesamiento de la información con base en la experiencia de quien aprende y, eventualmente, para qué aprende.

Las competencias se clasifican de diversas maneras; en algunos casos se ofrece la dicotomía entre duras y blandas, aunque en otras oportunidades se organizan en disciplinares, genéricas y transversales. Estas se transfieren a diferentes situaciones de la vida, entre ellas al desempeño profesional.

En este orden de ideas, las competencias profesionales (Galdeano y Valiente, 2010) son producto de los diferentes procesos de formación con la intervención de las instituciones educativas; el fin es lograr una preparación pertinente para la inserción en el ambiente laboral. En cuanto a las competencias laborales, la Organización Internacional del Trabajo (citada por Irigoin y Vargas, 2002) menciona lo siguiente:

[Se enfocan en] la construcción social de aprendizajes significativos y útiles para el desempeño productivo en una situación real de trabajo que se obtiene no solo a través de la instrucción, sino también — y en gran medida — mediante el aprendizaje por experiencia en situaciones concretas de trabajo (p. 10).

Las competencias laborales, pues, están enfocadas en el aprendizaje destinado al desempeño de la actividad para la cual se instruye al sujeto, por lo que se privilegia el aprendizaje situacional y en contexto para la aplicación de las habilidades y capacidades que se buscan promover. El Espacio Europeo de Educación Superior — a través de la Declaración de Bolonia (1999) - trató de lograr acuerdos entre los ministros europeos para desarrollar e implantar en sus países sistemas de titulaciones homologables para los niveles de postgrado con el fin de impulsar la movilidad, las oportunidades de trabajo y la competitividad de los sistemas educativos créditos. En la Declaración de Bolonia (1999) es innegable el alineamiento de esta iniciativa con la propuesta económica de la globalización y un discurso reiterado sobre la calidad en la educación.

Ahora bien, las competencias laborales en la cuarta revolución industrial también han sido catalogadas no solo como hard skills o habilidades duras — vitales para el desempeño de una profesión—, sino también como soft skills o habilidades blandas — esenciales para 
desarrollar rasgos de nuestra personalidad, comunicación, lenguaje, hábitos personales, etc.- . Por tanto, las competencias laborales para la cuarta revolución industrial pueden ser concebidas como aquellas que tienen que ver directamente con las habilidades básicas y las necesidades de aplicación práctica del conocimiento profesional en el entorno social y laboral actual, donde se imponen nuevos retos generados, en este caso concreto, por la covid-19.

Estas competencias requieren, como punto de partida, de las destrezas establecidas en los planes de estudios (es decir, saber aprender, conocimiento de sí mismo, competencias matemáticas, etc.), así como de las habilidades fijadas para el trabajo en cada disciplina (los abogados necesitan competencias de argumentación jurídica verbal y escrita; los médicos, conocer y comprender el funcionamiento del cuerpo humano, etc.). No obstante, hoy en día también son esenciales las competencias para desenvolverse dentro del mundo de la cuarta revolución industrial, lo que posibilitará un mayor éxito en el mercado laboral.

En ese sentido, organismos internacionales como la Organización Internacional del Trabajo, la Organización de las Naciones Unidas para la Educación, la Ciencia y la Cultura, la Comisión Económica para América Latina y el Caribe, la Organización para la Cooperación y el Desarrollo Económicos y la Unión Europea han desarrollado investigaciones sobre las competencias y habilidades que se deben tener para poder hacer frente al trabajo del futuro. En la tabla 1 se presentan aquellas que guardan similitudes: 
Revista lberoamericana

de las Ciencias Sociales y

Humanísticas

Tabla 1. Competencias laborales para la cuarta revolución industrial

\begin{tabular}{|c|c|c|}
\hline Organismo & Denominación & Categorías de competencias o habilidades \\
\hline $\begin{array}{l}\text { Organización para } \\
\text { la Cooperación y el } \\
\text { Desarrollo } \\
\text { Económico* }\end{array}$ & $\begin{array}{lr}\text { Habilidades } & \text { y } \\
\text { competencias del siglo } \\
\text { XXI para los } \\
\text { aprendices del nuevo } \\
\text { milenio }\end{array}$ & $\begin{array}{l}\text { - Competencias cognitivas: } \\
\text { alfabetización y aritmética. } \\
\text { - Competencias técnicas } \\
\text { (específicas del sector u } \\
\text { ocupación). } \\
\text { - Socioemocionales. } \\
\text { Trabajo en equipo y comunicación. }\end{array}$ \\
\hline $\begin{array}{l}\text { Organización de las } \\
\text { Naciones Unidas }\end{array}$ & $\begin{array}{lr}\text { Dinámicas } & \text { de } \\
\text { apropiación de las TIC }\end{array}$ & $\begin{array}{l}\text { - Habilidades } \\
\text { Pensamiento creativo, reflexivo, } \\
\text { racional y vinculante; } \\
\text { comunicación y colaboración, y } \\
\text { competencias laborales de la } \\
\text { industria 4.0. } \\
\text { - Habilidades digitales: Uso de las } \\
\text { tecnologías para elaborar y } \\
\text { compartir información. } \\
\text { - Habilidades curriculares. }\end{array}$ \\
\hline Unesco $^{* * * *}$ & $\begin{array}{l}\text { Competencias futuras } \\
\text { para la industria } 4.0\end{array}$ & 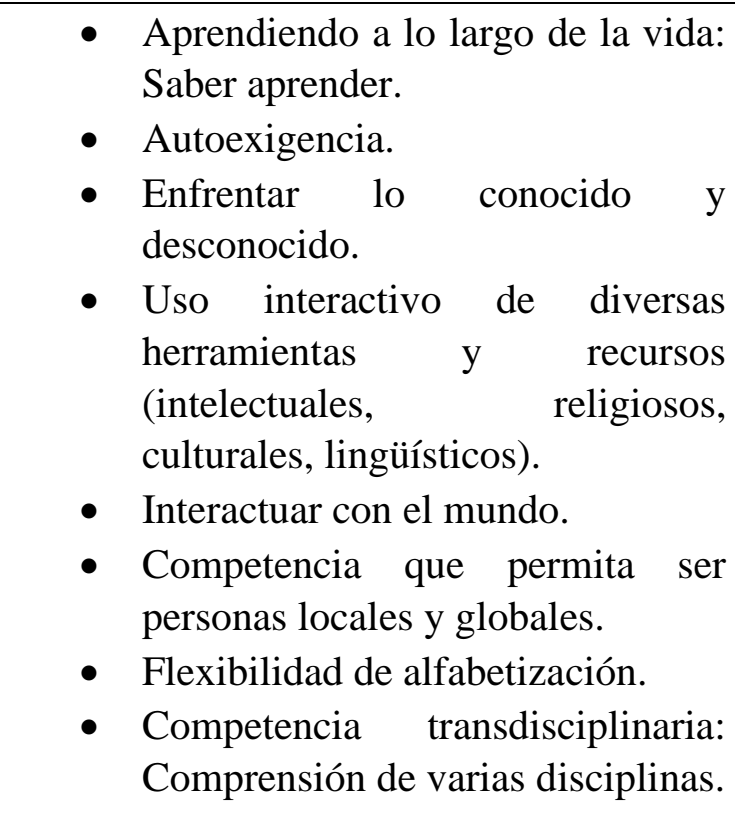 \\
\hline $\begin{array}{l}\text { Organización } \\
\text { Internacional del } \\
\text { Trabajo }^{* * * * *}\end{array}$ & $\begin{array}{l}\text { Competencias } \\
\text { laborales futuras }\end{array}$ & $\begin{array}{l}\text { - Habilidad de creación de sentido. } \\
\text { - Inteligencia social. } \\
\text { - Pensamiento innovador y } \\
\text { adaptativo. } \\
\text { - } \quad \text { Capacidades interculturales. } \\
\text { - Pensamiento computacional. } \\
\text { - Alfabetización en los nuevos } \\
\text { medios. }\end{array}$ \\
\hline
\end{tabular}




\begin{tabular}{|c|c|c|}
\hline & & $\begin{array}{l}\text { - Interdisciplina. } \\
\text { - Mentalidad diseñadora. } \\
\text { - Administración de la carga } \\
\text { cognoscitiva. } \\
\text { - Colaboración virtual. }\end{array}$ \\
\hline $\begin{array}{l}\text { Banco } \\
\text { Interamericano de } \\
\text { Desarrollo }\end{array}$ & $\begin{array}{l}\text { Habilidades híbridas } \\
\text { soft-hard }\end{array}$ & $\begin{array}{l}\text { - } \begin{array}{l}\text { Comprenden } \\
\text { socioemocionales, habilidades } \\
\text { cognitivas y y } \\
\text { acadilidades }\end{array} \\
\text { - } \begin{array}{l}\text { Comprendidades } \\
\text { ocupación, habilidades en el sector } \\
\text { y habilidades en la empresa. }\end{array}\end{array}$ \\
\hline
\end{tabular}

Fuente: Elaboración personal a partir de *OCDE, Habilidades y competencias del siglo XXI para los aprendices del nuevo milenio en los países de la OCDE; **Sunkel et al., La integración de las tecnologías digitales en las escuelas de América Latina y el Caribe, Chile: Naciones Unidas; ${ }^{* * *}$ Mmantsetsa et al., Future competences and the future of curriculum: United Nations Educational e International Bureau of Education (traducción personal); ****Catalano, Tecnología, innovación y competencias ocupacionales en la sociedad del conocimiento, Argentina: Organización Internacional del Trabajo. ${ }^{* * * * *}$ BID, Industría 4.0: fabricando el futuro. Argentina: BID.

\section{Retos de la educación 4.0}

La implementación de nuevos procesos en cualquier ámbito exige la superación de determinados retos para poder cumplir con su objetivo. En este sentido, la pandemia causada por el virus Sars-CoV2, al igual que la cuarta revolución industrial, han impuesto el reto de transformar nuestra formación académica en una educación 4.0, para lo cual se deben impulsar las siguientes iniciativas:

- Transformación de los centros educativos: Los planes de estudio y la infraestructura deberán actualizarse y modernizarse para atender las nuevas formas de impartir una enseñanza que responda a las necesidades de la industria 4.0.

- Formación del personal docente y administrativo de las instituciones educativas: La formación de los docentes permitirá promover el aprendizaje por competencias en un entorno multimodal. 
Revista Iberoamericana

de las Ciencias Sociales y

Humanísticas

ISSN: $2395-7972$

- Cambios en la metodología de aprendizaje: La implementación de la formación dual permitirá al estudiantado poner en práctica en el campo laboral el conocimiento teórico adquirido.

- Acceso a internet y medios tecnológicos: Contar con internet y medios tecnológicos abren la pauta para que el alumnado interactúe con los elementos más importantes de la era digital, ciertamente en conjunción con la formación impartida en aulas.

- Adquisición de competencias para el trabajo emergente: Cabe precisar que el concepto competencia incorpora el conjunto de conocimientos apropiados (saber) y las habilidades y destrezas (saber hacer) que una persona ha desarrollado para emplearlas en cada situación. Asimismo, incluye las condiciones del individuo y sus disposiciones a la acción con los componentes actitudinales y valorativos (saber ser).

\section{Competencias laborales para el trabajo emergente en tiempos de la cuarta revolución industrial y la covid-19}

A partir de lo planteado en los apartados anteriores, se puede asegurar que el mayor reto de la educación 4.0 en tiempos de la covid-19 es formar a los futuros profesionistas con competencias como las que se refieren a continuación para cumplir con éxito las tareas asignadas:

1. Pensamiento crítico y solución de problemas complejos: Esto demanda la capacidad para interpretar, analizar, evaluar, hacer inferencias, explicar y clarificar significados, por lo que se basa en el razonamiento lógico y la conciencia para respetar y refutar (cuando sea necesario) los puntos de vista ajenos en un contexto laboral cambiante (Fundación Omar Dengo [FOD], 2005).

2. Competencias digitales laborales: Se vinculan con el uso crítico y seguro de las tecnologías de la sociedad de la información para el trabajo, el tiempo libre y la comunicación. Esto significa el desarrollo de habilidades TIC básicas, como el uso de ordenadores para recuperar, evaluar, almacenar, producir, presentar e intercambiar información, y para comunicar y participar en redes de colaboración a través de internet.

3. Competencias socioemocionales para el trabajo 4.0: Son el conjunto de conductas, actitudes, rasgos y valores personales que contienen la capacidad para movilizar 
Revista Iberoamericana

de las Ciencias Sociales y

Humanísticas

ISSN: $2395-7972$

conocimientos, habilidades, destrezas y actitudes necesarios para regular las propias emociones en situaciones de interacción social, laboral y digital. Durante el confinamiento es particularmente importante contar con ellas, pues permiten la resiliencia emocional mientras se sigue siendo productivo pese a las adversidades.

4. Competencias para el trabajo transdisciplinar: Son el conjunto de conocimientos, saberes y habilidades de carácter científico y no científico tendientes a desarrollar la aptitud natural en los profesionistas para reconocer en las disciplinas su unidad, mediante la organización y articulación de conocimientos dispersos en las ciencias de la naturaleza, en las ciencias humanas, con el fin de comprender la unidad y la diversidad de todo lo que compete al ser humano para ser capaz de aplicarlo en las actividades laborales cambiantes (Tobón, 2013).

5. Competencias de aprendizaje permanente (saber reaprender): Es la capacidad regenerativa de reinventarse para adaptarse a las nuevas demandas profesionales (OCDE, 2019). Esto incluye desde el autoaprendizaje constante hasta el regreso a las universidades para reinventar la profesión aprendida y adaptarse al trabajo 4.0.

6. Competencias lingüísticas: Al respecto, el Marco Común Europeo de Referencia para las lenguas establece que la competencia lingüística es "la habilidad para expresar e interpretar pensamientos, sentimientos y hechos tanto de forma oral como escrita (escuchar, hablar, leer, escribir), y para interactuar lingüísticamente en un idioma extranjero de forma apropiada en contextos laborales innovadores" (Comisión Europea, 2004, p. 4). Lo anterior tiene que ver con la formación específica en un idioma de carácter técnico y especializado.

Ahora bien, el principal desafío para desarrollar estas competencias radica en la desigualdad y en la calidad de la educación que a lo largo de los años ha generado una brecha difícil de reducir. Por ejemplo, los resultados de la prueba PISA 2019 realizada por la OCDE demuestran que la mitad de los mexicanos no alcanza niveles suficientes para desenvolverse en la sociedad: en concreto, $45 \%$ no logra los aprendizajes suficientes en lectura, $56 \%$ en matemáticas y $47 \%$ en ciencias (Ortega, 3 de diciembre de 2019).

Asimismo, y con base en un informe presentado por el Instituto Mexicano para la Competitividad, solo la tercera parte de la población urbana que tiene entre 14 y 55 años de edad cuenta con algún conocimiento del idioma inglés. De hecho, de quienes señalan que conocen dicha lengua, solamente cuatro de cada 100 pueden leerla y entenderla, y dos de 
cada 100 pueden hablarla y escribirla muy bien (Instituto Mexicano para la Competitividad [IMCO], 2015).

\section{Conclusiones}

La llegada de la cuarta revolución industrial y la pandemia de la covid-19 generarán a corto plazo un gran cambio en todos los ámbitos de la vida, lo que provocará el surgimiento de un proceso de adaptación que deberá ser promovido desde los ámbitos educativos, espacios que deben brindar las herramientas necesarias para que mujeres y hombres puedan desempeñarse con éxito en los emergentes mercados laborales.

Esto, por supuesto, exigirá el desarrollo de competencias vinculadas principalmente con la industria 4.0, es decir, habilidades para manipular dispositivos digitales, pensamiento crítico para la solución de problemas complejos, competencias socioemocionales para el trabajo 4.0, competencias para el trabajo transdisciplinar, competencias de aprendizaje permanente (saber reaprender) y competencias lingüísticas.

En pocas palabras, se debe apostar por la capacitación de profesiones y ocupaciones propias del mundo digital; sin embargo, también se debe tomar en cuenta lo señalado por Portella (28 de septiembre de 2018) cuando enfatiza que "78 \% de los estudiantes mexicanos de 18 años no están interesados en ciencia, y $50 \%$ de los egresados eligen entre 9 carreras, solo una de ellas (ingeniería industrial) relacionada con ciencia, tecnología, ingeniería y matemáticas" (párr. 2). Esto demuestra que se están obviando aquellas carreras altamente demandas en el mercado laboral del futuro, por lo que se deben concretar indagaciones que se enfoquen en analizar este fenómeno con el fin de impulsar un cambio de actitud en las nuevas generaciones. 
Revista Iberoamericana

de las Ciencias Sociales y

Humanísticas

ISSN: $2395-7972$

\section{Referencias}

Blanco, M. (19 de julio de 2018). Profesiones digitales con más futuro y nuevas formas de trabajo. El Economista. Recuperado de https://www.eleconomista.es/ecoaula/noticias/9284172/07/18/Profesiones-digitalescon-mas-futuro-y-nuevas-formas-de-trabajo.html

Cataldi, Z. y Dominighini, C. (2015). La generación millennial y la educación superior. Los retos de un nuevo paradigma. Revista de Informática Educativa y Medios Audiovisuales, 12(19), 14-21.

Castresna, C. (2015). Industria 4.0. Madrid, España: Universidad de la Rioja. Recuperado de https://biblioteca.unirioja.es/tfe_e/TFE002004.pdf

Comisión Europea (2004). Competencias clave para un aprendizaje a lo largo de la vida. Un marco de referencia europeo. Bélgica: Dirección General de Educación y Cultura.

Declaración de Bolonia (1999). Declaración de Bolonia. Recuperado de http://www.educacion.gob.es/boloniaensecundaria/img/Declaracion_Bolonia.pdf

Deloitte (2019). La cuarta revolución industrial está aquí. ¿Está usted preparado? Colombia: Deloitte. Recuperado de https://www2.deloitte.com/content/dam/Deloitte/uy/Documents/humancapital/Revoluci\%C3\%B3n\%204.0.pdf

Echeverría, B. y Martínez, P. (2018). Revolución 4.0, competencias, educación y orientación. Revista Digital de Investigación en Docencia Universitaria, 12(2), 4-34. Doi: https://dx.doi.org/10.19083/ridu.2018.831

Federal Student Aid (s. f.). Arquitecto de base de datos. Estados Unidos de América: Federal Student Aid. Recuperado de https://studentaid.ed.gov/sa/es/prepare-forcollege/students/career-search/profile/summary/15-1199.06

Foro Económico Mundial [FEM] (2018). The Future of Jobs Report. Suiza: WEF. Retrieved from http://www3.weforum.org/docs/WEF_Future_of_Jobs_2018.pdf

Fundación Mapfre (2019). El desafío de las tecnologías educación 4.0. España: Educatumundo.

Recuperado de https://www.fundacionmapfre.org/fundacion/es_es/images/desafio-tecnologiaseducacion-libro-profesor_tcm1069-421445.pdf

Fundación Omar Dengo [FOD] (2005). Pensamiento crítico. Costa Rica: FOD. Recuperado de http://www.fod.ac.cr/competencias21/index.php/areas-de-recursos/videos/14- 
Revista Iberoamericana

de las Ciencias Sociales y

Humanísticas

ISSN: $2395-7972$

competencias/fichas/8-pensamiento-critico-resolucion-de-problemas-y-toma-dedecisiones

Galdeano, C. y Valiente, A. (2010). Competencias profesionales. Educación Química, 21(1), 28-32.

Recuperado

de http://www.scielo.org.mx/scielo.php?script=sci_arttext\&pid=S0187$893 X 2010000100004 \& \operatorname{lng}=e s \& t \operatorname{lng}=e s$

Galindo, M. (2015). Lectura crítica hipertextual en la web 2.0. Revista Electrónica Actualidades Investigativas en Educación, 15(1), 1-29. Recuperado de http://www.redalyc.org/articulo.oa?id=44733027016

Garay, L. (2017). Alfabetización digital, programas oficiales y realidades de aprendizaje. Trayectorias de universitarios activistas de colectivos estudiantiles. En Congreso Nacional de Investigación Educativa. COMIE. Recuperado de www.comie.org.mx/congreso/memoriaelectronica/v14/doc/1641.pdf

Gasca, M. (2010). Desarrollo de la literacidad crítica en internet en estudiantes mexicanos de bachillerato. Ponencia presentada en el Congreso Internacional Europa/América Latina ATEI: Alfabetización mediática y culturas digitales. Recuperado de https://dialnet.unirioja.es/servlet/articulo?codigo=4154216

Instituto Mexicano para la Competitividad [IMCO] (2015). Inglés es posible: propuesta de Agenda Nacional. México.

Irigoin, M. y Vargas, F. (2002). Competencia laboral. Manual de conceptos, métodos y aplicaciones en el Sector Salud. Suiza: OIT-OPS.

Lahera, A. (2019). Digitalización, robotización, trabajo y vida: cartografías, debates y prácticas. Cuad. Relac. Labor., 37(1), 249-273. Recuperado de https://revistas.ucm.es/index.php/CRLA/article/view/66037

Linkedin (2017). The digital workforce of the future. Linkedin, Estados Unidos de América: Linkedin. Retrieved from https://business.linkedin.com/content/dam/me/business/enus/talent-solutions/cx/2017/PDFs/digital_workforce_future.pdf

Lombardero, L. (2015). Trabajar en la era digital: tecnología y competencias para la transformación digital. España: Lid Editorial Empresarial.

Mendizábal, G. y López, E. (2018). ¿Nuevo modelo de seguridad social en el contexto de la Industria 4.0? Revista Internacional y Comparada de Relaciones Laborales y Derecho del Empleo, 1(6), 298-327. 
Revista Iberoamericana

de las Ciencias Sociales y Humanísticas

ISSN: $2395-7972$

Menéndez, R. (2020). 14 profesiones con mucho futuro. Infojob. Recuperado de https://orientacion-laboral.infojobs.net/14-profesiones-con-futuro

Organización Mundial de la Salud [OMS] (2020). Preguntas y respuestas sobre la enfermedad por coronavirus. Suiza: OMS.

Organización Panamericana de la Salud [OPS]. (2020). La OMS caracteriza a COVID-19 como una pandemia. Estados Unidos de América: OPS.

Organización para la Cooperación y el Desarrollo Económico [OCDE] (2019). El trabajo de la OCDE sobre educación y competencias. Francia: OCDE. Recuperado de https://www.oecd.org/education/El-trabajo-de-la-ocde-sobre-educacion-ycompetencias.pdf

Ortega, A. (3 de diciembre de 2019). 10 datos sobre la educación en México, según la más reciente prueba PISA. Expansión. Recuperado de https://politica.expansion.mx/mexico/2019/12/03/10-datos-sobre-la-educacion-enmexico-segun-la-mas-reciente-prueba-pisa

Perrenoud, P. (2004). Diez nuevas competencias para enseñar. México: SEP. Recuperado de http://edu.jalisco.gob.mx/cepse/sites/edu.jalisco.gob.mx.cepse/files/diez_comp.pdf

Portella, A. (28 de septiembre de 2018). El futuro del empleo en México está en la ciencia y la tecnología. Forbes. Recuperado de https://www.forbes.com.mx/el-futuro-delempleo-en-mexico-esta-en-la-ciencia-y-la-tecnologia/

Quiroz, M. y Norzagaray, C. (2017). Literacidad digital en el entorno académico de los estudiantes universitarios. Congreso Nacional de Investigación Educativa COMIE. Recuperado de www.comie.org.mx/congreso/memoriaelectronica/v14/doc/2946.pdf

Real Academia de la Lengua (2014). Diccionario de la lengua española (23. ${ }^{a}$ ed.). España: Real Academia Española. Recuperado de http://dle.rae.es/?id=ZJ2KRZZ

Sánchez, E. (2008). Las tecnologías de información y comunicación (TIC) desde una perspectiva social. Revista Electrónica Educare, 1(12), 155-162.

Swain Oropeza, R. (2017). Modelo educativo para la industria 4.0. México: Academia de Ingeniería. Recuperado de https://es.slideshare.net/AcademiaDeIngenieriaMx/modeloeducativo-para-laindustria-40

Tobón, S. (2013). Formación integral y competencias: pensamiento complejo, currículo, didáctica y evaluación. Colombia: ECOE. 


\section{Revista Iberoamericana de las Ciencias Sociales y Humanísticas}

Universidad Autónoma del Estado de Morelos [UAEM] (2020). Modelos universitario 2020. México: UAEM.

Ynzunza, C., Izar, J., Bocarando, J., Aguilar, F. y Larios, M. (2018). El entorno de la industria 4.0: implicaciones y perspectivas futuras. Revista Conciencia Tecnológica, (54). Recuperado de https://www.redalyc.org/jatsRepo/944/94454631006/html/index.html

\begin{tabular}{|c|c|}
\hline Rol de Contribución & Autor (es) \\
\hline Conceptualización & Gabriela Mendizábal Bermúdez \\
\hline Metodología & Ana Esther Escalante Ferrer \\
\hline Software & Ana Esther Escalante Ferrer \\
\hline Validación & Ana Esther Escalante Ferrer \\
\hline Análisis Formal & $\begin{array}{l}\text { Ana Esther Escalante Ferrer 50\% } \\
\text { Gabriela Mendizábal Bermúdez 50\% }\end{array}$ \\
\hline Investigación & $\begin{array}{l}\text { Ana Esther Escalante Ferrer 50\% } \\
\text { Gabriela Mendizábal Bermúdez 50\% }\end{array}$ \\
\hline Recursos & $\begin{array}{l}\text { Ana Esther Escalante Ferrer 50\% } \\
\text { Gabriela Mendizábal Bermúdez 50\% }\end{array}$ \\
\hline Curación de datos & $\begin{array}{l}\text { Ana Esther Escalante Ferrer 50\% } \\
\text { Gabriela Mendizábal Bermúdez 50\% }\end{array}$ \\
\hline $\begin{array}{l}\text { Escritura - Preparación del } \\
\text { borrador original }\end{array}$ & Gabriela Mendizábal Bermúdez \\
\hline Escritura - Revisión y edición & $\begin{array}{l}\text { Ana Esther Escalante Ferrer 50\% } \\
\text { Gabriela Mendizábal Bermúdez 50\% }\end{array}$ \\
\hline Visualización & $\begin{array}{l}\text { Ana Esther Escalante Ferrer 50\% } \\
\text { Gabriela Mendizábal Bermúdez 50\% }\end{array}$ \\
\hline Supervisión & Gabriela Mendizábal Bermúdez \\
\hline Administración de Proyectos & Gabriela Mendizábal Bermúdez \\
\hline Adquisición de fondos & Gabriela Mendizábal Bermúdez \\
\hline
\end{tabular}

